\title{
The Mother Archive: Immersion, Affect and the Maternal in Museum Practice
}

Rebecca Louise Clarke

Monash University

\begin{abstract}
In a discussion of my digital archive project, 'The Mother Archive', I ask: what would a museum program about motherhood look and sound like? Identifying an absence of motherhood and the maternal as curatorial themes in Australian museums, I argue for a need to address maternal experience in museum practice. I then ask: how can digital technologies be used in museum settings to give us greater insight into maternal experiences? I suggest that the immersive technology of virtual reality (VR) could lead us to a deeper understanding of maternal subjectivity by enabling affective encounters. The immersive potential of VR has been used in areas including psychology (for instance trauma recovery) and workplace training. But its capacity to achieve affect in the context of museum environments has not been explored fully in scholarly work. While there is much conceptualising of VR as a tool of embodiment and empathy, there is no known scholarly work on how VR might enable us to engage with maternal subjectivity. My project strives to fill this gap in knowledge by creating a digital archive representing actual experiences of mothering as voiced by mothers.
\end{abstract}

How does a mother make sense of her maternal experiences? The wellknown What to Expect When You're Expecting, first published in 1984, now in its fifth edition, remains on the New York bestseller list. This book, along with countless websites targeted at expectant mothers, aims to educate women about each stage of their pregnancy. In this sense, there is little room for perspectives on 'matrescence', the transformation of first-time 
motherhood, outside the parameters of medical language. ${ }^{1}$ My project, 'The Mother Archive' strives to create a digital archive of 'inobservable worlds' the actual experiences of matrescence as voiced by mothers. ${ }^{2}$

'The Mother Archive' is an interdisciplinary $\mathrm{PhD}$ project based at Monash University. This project is informed by my curatorial research at Museums Victoria (MV) on their mother-related collection material, and my experiments with digital technologies to create an archive of maternal experiences, based at Monash University's SensiLab. The aim of this project is to design a digital, immersive archive of motherhood (and maternal experiences) using digital technologies (including, for instance, virtual reality (VR), immersive sound design, and motion capture technology), with the aim of articulating experiences of mothering. The immersive potential of VR has been used in areas including psychology (for instance, trauma recovery) and workplace training. But its capacity to achieve affect in the context of heritage environments has not been explored fully in scholarly work. While there is much conceptualising of VR as a tool of embodiment and empathy, there is no known critical attention to how VR might enable us to engage with maternal subjectivity. My research seeks to fill this gap in knowledge by imagining how VR might be used in the creation of a 'mother archive' to be displayed in museum settings. By experimenting with immersive technologies including VR, I seek representations that challenge dominant discourses on motherhood. My project aims to bring more visibility to the role mothers have played in Australian history by representing maternal experiences in museum settings.

In my practice-led research, I explore how immersive experiences might lead us to an embodied connection with maternal subjectivities. I suggest that various characteristics of maternal experience (for example, emotional

1 I would like to thank Professor Therese Davis, Dr Thomas Chandler, Dr Joanne Evans and Dr Vince Dziekan at Monash University for their thoughtful comments and encouragement. I would also like to thank Dr Carla Pascoe Leahy, at University of Melbourne, and MV Senior curator Deborah Tout Smith for generously offering me their time and expertise, and VR filmmaker Sojung Bahng for her valuable insights on VR cinema. I also acknowledge the support of the Australian Government Research Training Program Scholarship and the Robert Blackwood Museums Victoria - Monash University Partnership Award in the writing of this article. Dana Raphael, 'Matrescence, Becoming a Mother, a "New/Old” Rite De Passage', in Being Female: Reproduction, Power and Change, ed. Dana Raphael (Berlin: Walter de Gruyter, 1975), 65-71, doi.org/10.1515/9783110813128.65.

2 Anne E Sexton and Dolly Sen, 'More Voice, Less Ventriloquism: Exploring the Relational Dynamics in a Participatory Archive of Mental Health Recovery', International Journal of Heritage Studies, 24, no. 8, (2018): 847, doi.org/10.1080/13527258.2017.1339109. 
connections to one's child, and atmospheric sounds and images specific to the environment of mothering) are intangible in nature, and then go on to explore how techniques of digital immersion might enable us to better engage with intangible heritage (the intangible heritage of mothering might include, for instance, oral histories, soundscapes, religious and cultural rituals) and lead us into a more profound understanding of maternal experiences by enabling affective encounters. Drawing on my experiments, I analyse the ways that VR might enable us to challenge and disrupt dominant discourses on motherhood, discourses that commonly spring from realms of medical language, nostalgia and Western notions of the ideal mother. By making the subjective inner-worlds of mothers a primary concern in my work, my research offers contributions to the fields of maternal studies, museum studies and immersive technologies, including VR cinema.

This article asks: how can we represent the inner-world of mothers and 'maternal subjectivity' in museum collections and programs? First, I identify an absence of 'motherhood' and maternal experience as curatorial themes in Australian museum collections and programs. Drawing on my current curatorial research at MV in which I study mother-related collections, I identify gaps in MV's collection and programs and argue for a need to address maternal experience. I then ask: what would an exploration of the theme of motherhood in museums look and sound like? I propose that a collection on motherhood, or what I will call a 'mother archive', can best be facilitated by curatorial practice that employs techniques of immersion, affect and the model of the 'relational museum', and that digital technologies offer us valuable tools to realise these techniques. ${ }^{3}$ I then ask: how might VR help with conceptualising a 'mother archive'? I suggest that VR, with its potential for creating embodied understanding could contribute much value to exhibitions displaying mother-related content and could provide some of the valuable tools we need to come to a closer understanding of maternal subjectivity. In a discussion on my own experiments with VR, I explore the ways that VR might offer us representations of the maternal that challenge dominant discourses on motherhood and can lead us into a deeper understanding of the maternal experience by enabling affective encounters.

3 For more information see: Michael Alistair Jones, 'Documenting Artefacts and Archives in the Relational Museum' (PhD thesis, School of Historical and Philosophical Studies, University of Melbourne, December 2018). 
Perhaps at first glance, mothering could be considered just too quotidian for a museum collection or exhibition. A 'mother archive' might necessarily entail a focus on the banal and everyday, and consequently a resistance to grand narratives and monumentality, components considered central to notions of nationhood. Museum scholar Laurajane Smith critiques museums' privileging of grand narratives, and what Smith terms 'authorised heritage discourse', suggesting that heritage institutions value the monumental over the banal as a necessary upholding of national pride. ${ }^{4}$ Smith points out that often the events being 'remembered' by museums are dramatic in their significance and although negative events are preserved by museums, it is the exceptional that is favoured over the ordinary:

Even when it is the "bad" that is being preserved, it is very often the exceptionally "tragic" event that is being commemorated, rather than unpleasantness that is more mundane or reflective of the general inequalities of human experience. ${ }^{5}$

I argue that it is the 'stories of quiet heroism' that need more attention in Australian history and deserve to be represented. ${ }^{6}$ As maternal scholars such as Anne Manne, Petra Bueskens and Maria Tumarkin argue, the role of caregiver is under-valued and under-represented in contemporary Australian society. ${ }^{7}$ My project aims to bring more visibility to the role mothers have played in Australian history by representing maternal experiences in museum settings.

A survey of online museum catalogues reveals that rarely has motherhood been granted contemplation as a curatorial theme in museum collections and programs. The Victoria \& Albert (V\&A) Museum of Childhood in London holds childhood collections relevant to children and family, but there is no collection thematically concerned with motherhood. ${ }^{8}$ In the US, the Smithsonian recently ran the exhibition 'Picturing Motherhood' that displayed photography and paintings depicting representations of mothers in fine art. ${ }^{9}$ While this exhibition sheds light on the way motherhood has been represented throughout history, the inner-world of mothers, or maternal subjectivity, remains largely absent as a curatorial

4 Laurajane Smith, Uses of Heritage (Abingdon: Routledge: 2006), 23.

5 Ibid.

6 Anne Manne, 'Mothers and the Quest for Social Justice', in Dangerous Ideas About Mothers, eds. Camilla Nelson and Rachel Robertson (Perth: University of Western Australia Publishing, 2014), 23.

7 Ibid., 25; Petra Bueskens, 'Containing to Creating, Maternal Subjectivity', in ibid., 197-210; Maria Tumarkin, 'Against Motherhood Memoirs', in ibid., 86.

8 Museum of Childhood, Victoria and Albert Museum (V\&A), www.vam.ac.uk/moc.

9 'Picturing motherhood', Smithsonian, www.si.edu/spotlight/mothers-day. 
concern. The Museum of Motherhood (MOM), based in New York is a unique case as the only known museum devoted specifically to the theme of motherhood. ${ }^{10}$ Founded by adjunct professor of motherhood studies, Martha Joy Rose of Manhattan College, the museum houses a collection of objects ranging from the political (for example, activist pamphlets) to the personal (including personal testimonies authored by mother writers and artists) with an emphasis on public education and feminist activism. ${ }^{11}$ At a local level, as of yet there is no known Australian museum that focuses on motherhood (or maternal experience) as a curatorial theme. In Australian museum collections, the topic of motherhood is often raised in the peripheral, as a side note to other issues, which serve as the focus of collections such as women's movements, childhood and immigration. The representation of mothers in museum collections and programs is also a neglected area of interest in scholarly work.

In the following section, I focus my attention to mother-related collections at MV and argue for a need to explore experiences of mothering in museums collections and programs.

\section{Museums Victoria (MV): A Case Study}

Currently, MV's collection holds over 17 million items, including objects relating to Indigenous Australian and Pacific Islander cultures, geology, historical studies, palaeontology, technology and society, and zoology. ${ }^{12}$ MV was first established as the National Museum of Victoria in 1854, which had a primary focus on natural sciences. In 1870 , the Industrial and Technological Museum was established to research, collect and display scientific and technological advances. When the two institutions were brought together in 1983, social history was added as a further research and collecting area. In 2016, the museum was renamed Museums Victoria (MV) and now encompasses Melbourne Museum, Immigration Museum, Royal Exhibition building, Scienceworks, Bunjilaka and IMAX cinema. These sites, all residing in Melbourne, Victoria, are major tourist attractions and education sites for those visiting Melbourne. For instance, the Melbourne Museum in Carlton houses permanent exhibitions on the history of Melbourne and, more recently, Indigenous history, which

10 Museum of Motherhood (MOM), mommuseum.org.

11 Ibid.

12 'Collections', Museums Victoria, collections.museumsvictoria.com.au. 
attracts international visitors and school excursion groups. Currently, MV holds a collection of over 17 million items, held in storage facilities at Melbourne Museum, Scienceworks and a specialised storage facility.

The recent development of MV's Pauline Gandel children's gallery demonstrates MV's awareness that children visitors (both within school excursion groups and families) are vital to the survival of their museums. ${ }^{13}$ Over one third of all visitors to Melbourne Museum are families, and yet in exhibits, parents, carers and experiences of mothering are not specifically being addressed. In MV's Collection Plans 2013 - 2018, which summarises the aims and future directions of their collections, motherrelated collections include: Childhood, Migration and Cultural Diversity, Medicine and Health, and Home and Community. ${ }^{14}$ These categories have been formed thematically by curators and consist of material that can be found on MV's catalogue system EMu. Keywords and subjects recognised in the EMu system do not include 'mother' and 'maternal', but instead can be found indirectly through broader terms such as 'domestic life'.

MV have made efforts to include marginalised voices in their programs by curating collections and exhibits that engage with indigenous cultures, and seek out a counter-narrative to white colonial perspectives. For example, the Bunjilaka Aboriginal cultural centre at Melbourne Museum has a permanent exhibition on Indigenous cultures and MV's Immigration Museum has hosted programs addressing themes of cultural diversity and immigration histories. MV's recent exhibition 'WWI: Love and Sorrow', which commemorated the 100-year anniversary of WWI, paid substantial attention to the experiences of families of war (including mothers of war soldiers). ${ }^{15}$ These developments at MV show an enthusiasm to engage with the concerns of marginalised groups and a willingness to re-consider

13 Pauline Gandel children's gallery, museumsvictoria.com.au/melbournemuseum/whats-on/ childrens-gallery/. It cannot be confirmed exactly how many mothers visit MV, although this author has observed (as a mother and frequent visitor myself) the Melbourne museum is commonly frequented by mothers and their children. MV keeps records of their visitor statistics in their ticketing system, though details such as gender are not documented, which makes specific characteristics of visitors hard to decipher.

14 Carla English (ticketing records officer) interview with Rebecca Louise Clarke (Melbourne, 17 March 2020); Museums Victoria, Collection Plans 2013 - 2018 (Melbourne: Museums Victoria, July 2013).

15 For more information, see Deborah Tout-Smith, 'Love \& Sorrow: The Role of Emotion in Exhibition Development and Visitor Experience', in Emotion and the Researcher: Sites, Subjectivities, and Relationships, Studies in Qualitative Methodology, Vol. 1, eds. Tracey Loughran and Dawn Mannay (Bingley, United Kingdom: Emerald Publishing Limited, 2018), 159-76, doi.org/10.1108/ s1042-319220180000016011. 
what might constitute 'heritage' in innovative, museum practice. For instance, their recent exhibition 'Love' held at the Immigration Museum demonstrated an approach to curatorial practice that groups collection material into a broader theme of 'love' in all its varying definitions, without being anchored to a particular time period or geographical location. This demonstrates MV's growing interest in taking thematic approaches to their exhibit concepts. But maternal experience as a thematic focus has not yet been explored.

Recent projects have taken a look at motherhood in MV's collections. Melbourne historian and author Dr Carla Pascoe Leahy has undertaken a substantial body of work on the history of childhood, which has included archival research on MV's childhood collection. Pascoe Leahy is currently conducting oral histories from several generations of Australian mothers to analyse how understandings of 'selfhood, work, care, and gender have played out in the lives of mothers from 1946 to the present' ${ }^{16}$ These oral histories will be acquired by MV as part of their collection. MV curator Liza Dale-Hallett has played a pioneering role in the development of women-centred collections at MV. Dale-Hallett initiated The Invisible Farmers Project, a collection that focuses on women farmers (often wives and mothers) who have played crucial roles, often involving the 'invisible' labour (for instance, domestic labour and child rearing) important to farming life in Australia. Dale-Hallett's project, which still thrives with an active online MV blog, was created when Dale-Hallett put forward the strong argument that a collection is needed that acknowledges unpaid domestic labour and that rural women and mothers should have a vocal place in the history of Australia. Rural women's invisible labour has since had a place in MV's collection in the form of objects and oral histories. ${ }^{17}$ However, while written transcripts are available via EMu and snippets of interviews displayed on the Invisible Farmers project blog on the MV website, generally the museum visitor is unlikely to hear these voices.

The William Boyd Childhood Collection, housed in MV's Childhood Collection, is another collection that offers glimpses of maternal experiences. The collection consists of over 700 objects, including most of the childhood possessions of William (Bill) Boyd, encompassing

16 Carla Pascoe Leahy, 'The Experience of Becoming a Mother since 1945', Australian Research Council (DECRA) project, University of Melbourne, 2018.

17 Barbara Pini, Ruth Panelli, and Liza Dale-Hallett, 'The Victorian Women on Farms Gatherings: A Case Study of the Australian "Women in Agriculture" Movement', Australian Journal of Politics \& History, 53, no. 4 (2007): 569-80, doi.org/10.1111/j.1467-8497.2007.00475.x. 
toys, books, clothing and other items that Bill and his mother collected. The MV website describes the collection as demonstrating a range of prominent themes in the lives of postwar Victorian children, such as the ability to 'make do' under harsh circumstances and the changes in toy manufacturing (towards plastic materials and mass production), the prominence of gender roles, and the popularity of transport- and warthemed toys for boys. ${ }^{18}$ The collection was passed onto Bill after his mother's death and eventually donated to the Museum of Childhood at Edith Cowan University in Western Australia (when the Museum of Childhood closed it was transferred to the Museum Victoria in 2009). This collection, I suggest, also reveals the ways that Bill's mother, Lillian Boyd, archived her experiences of motherhood. The objects have been exhibited in contexts outside of motherhood specifically, to address national concerns. For instance, objects from the William Boyd collection have been displayed as part of exhibitions concerned with immigration histories and Melbourne history, and have an online presence on the MV blog in which their national significance is discussed. ${ }^{19}$

I suggest that if the mother-related collections that I have outlined were to be explored under the thematic umbrella of motherhood, a different set of concerns could then be addressed and much could be learned about experiences of maternal subjectivity. For instance, it would be interesting to know what these objects represented to Lillian Boyd personally and why she chose to order them in a certain way. If we consider the mother as archivist, in this light, it could also be considered that a mother's collected objects place her on display as a parent. In this sense, it would be worth examining whether the act of archiving involves a performance of motherhood in a self-conscious or idealised way, favouring nostalgia over challenging realities. What Lillian Boyd and her son kept reveals a lot about how clothes were made, how children were taken care of, and the available domestic technologies of the time. I suggest that what is missing from this collection are the more banal, everyday 'things' of matrescence, specifically the voice of the mother and access to her experiences of early motherhood in all its chaos and messiness.

I suggest that digital technologies could offer us intimate encounters with the intangible aspects of mothering. As digital humanities theorist and curator Sarah Kenderdine observes, digital technology offers valuable

18 'William Boyd Collection', Museums Victoria, collections.museumvictoria.com.au/articles/1622.

19 Ibid. 
tools to display intangible cultural heritage. ${ }^{20}$ Intangible heritage, which can include oral traditions, expressions and language, can be preserved or re-enacted with the assistance of technologies such as motion capture, VR and immersive storytelling. ${ }^{21}$ Intangible aspects of motherhood hold potent elements of maternal subjectivity and a 'mother archive' could articulate these aspects with the use of digital technology. In what follows, I outline a 'mother archive' that articulates experiences of motherhood as voiced by mothers.

\section{The Mother Archive: Theory}

The 'mother archive' is woven from oral histories, objects and images drawn from maternal experiences-my own and those close to me including, for instance, my mother, mother-in-law and aunt. Inspired by my own experience of becoming a mother for the first time, it is a deeply personal project, which does not seek to define any universal experience of mothering but rather to articulate aspects of complex and hard-todefine maternal subjectivities and to ask: how might digital technology afford us opportunities to experience aspects of maternal subjectivities in a museum setting?

In my role as curator, I employ a practice-led methodology to imagine what a 'mother archive' might look and sound like. Practice-led methodology allows me to illustrate theories with practical experiments relevant to the industry or practice-in this case, the industry of museums and the practice of curatorship, which my project seeks to illuminate. Practice-led research is 'concerned with the nature of practice' (in my case, curatorial practice) and leads to 'new knowledge that has operational significance for that practice. The main focus of the research is to advance knowledge about practice, or to advance knowledge within practice.' 22

\footnotetext{
20 For further information, see Sarah Kenderdine and Jeffrey Shaw, 'Archives in Motion', in Museum and Archive on the Move: Changing Cultural Institutions in the Digital Era, ed. Wendy Coones and Viola Rühse (Berlin: Walter de Gruyter GmbH \& Co KG, 2017), 211, doi.org/10.1515/9783110529630. 21 Intangible heritage has been defined as including: performing arts, social practices, rituals and festive events, knowledge, traditional craftsmanship. See Huib Schippers, 'Applied Ethnomusicology and Intangible Cultural Heritage', in The Oxford Handbook of Applied Ethnomusicology, eds. Svanibor Pettan and Jeff Todd Titon (Oxford: Oxford University Press, 2015), 134-56, doi.org/10.1093/ oxfordhb/9780199351701.013.7.

22 Linda Candy, 'Practice based research: A guide', CCS report 1 (2006): 1-19.
} 
My research draws on the approach employed by qualitative researchers (rather than by logical and statistical procedures) who 'use multiple systems of inquiry for the study of human phenomena including biography, case study, historical analysis, discourse analysis, ethnography, grounded theory and phenomenology'. ${ }^{23}$ My methodology is based on the assumptions that 'knowledge is subjective rather than objective' and that I learn from the participants in order to 'understand the meaning of their lives'. ${ }^{24}$

Given that my subjects of study include myself and those close to me, I use autoethnography, which seeks to analyse personal experience (auto) in order to understand cultural experience. It is value centred rather than pretending to be value free. As Carolyn Ellis, Tony E Adams and Arthur P Bochner describe it in the journal Forum: Qualitative Social Research:
When researchers write autoethnographies, they seek to produce aesthetic and evocative thick descriptions of personal and interpersonal experience. They accomplish this by first discerning patterns of cultural experience evidenced by field notes, interviews, and/or artefacts, and then describing these patterns using facets of storytelling (e.g., character and plot development), showing and telling, and alterations of authorial voice. Thus, the auto-ethnographer not only tries to make personal experience meaningful and cultural experience engaging, but also, by producing accessible texts, she or he may be able to reach wider and more diverse mass audiences that traditional research usually disregards, a move that can make personal and social change possible for more people. ${ }^{25}$

In order to explore the representation of maternal subjectivity in VR, I apply the following technology applications: I create a VR 360-degree video scene, I collect oral history recordings and atmospheric sound recordings, and I apply immersive soundscapes to the VR 360-degree environment. In my collection of VR works, I investigate maternal subjectivity through an exploration of the messy, banal, hard to articulate and hard to define everyday-ness of mothering. It is through this exploration that the normal and banal are made interesting, surprising and strange, allowing for a critique of assumptions we have in Australian society about motherhood,

23 Carolyn Ellis, Tony E Adams, Arthur P Bochner, 'Autoethnography: an Overview', Forum: Qualitative Social Research, 12, no. 1 (2011): 273-90.

24 Ibid.

25 Ibid. 
the cultural expectations placed on the 'mother' identity and a critique on archival practice that frames representations of (and produces knowledge about) motherhood.

\section{Maternal Subjectivity}

How can the complex experience of becoming a mother be defined? Medical anthropologist Dana Raphael coined the term 'matrescence' in 1975 to describe the experience of becoming a mother for the first time. ${ }^{26}$ Since then the term has been used by maternal scholars in their explorations of what it might mean to become a mother. I argue that, as leading Australian maternal scholars Petra Bueskens and Alison Stone suggest, maternal subjectivity needs to be thoroughly explored in order to free representations of motherhood from clichéd paradigms. ${ }^{27}$ Stone, drawing on psychoanalytic theory, argues that were cultural assumptions about motherhood to be changed, what is normally considered the 'natural fact' of mothering could be experienced differently and that maternal subjectivity could then be more easily understood. ${ }^{28}$ Interestingly, Stone suggests that maternal subjectivity would not be subjectivity-as-usual but rather specifically maternal: 'a specific form of subjectivity that is continuous with the maternal body, both the body of the one who mothers now and, in memory and fantasy, the one who mothered her, the mother's mother'. ${ }^{29}$

My exploration is most inspired by features of maternal subjectivity described by creative writer and historian Sarah Knott and maternal scholar and psychotherapist Lisa Baraitser. ${ }^{30}$ The characteristics Knott and Baraitser attribute to maternal subjectivity have informed my experiments because they have resonated most with my own experience of mothering. Knott's 2019 Mother: An Unconventional History was written when Knott became pregnant with her first child. Knott sought to make sense of her experience by seeking out the forgotten histories of motherhood from different communities as far back as the sixteenth century. Knott's creative narrative includes her anecdotes from her own life, which are intermingled

26 Raphael, 'Matrescence', 65-71.

27 Bueskens, 'Containing to Creating', 197.

28 Alison Stone, Feminism, Psychoanalysis, and Maternal Subjectivity (Abingdon: Routledge, 2013).

29 Ibid., 3.

30 Sarah Knott, Mother: An Unconventional History (London: Penguin, 2019); Lisa Baraitser, Maternal Encounters: The Ethics of Interruption (Abingdon: Routledge, 2008). 
and contrasted with those of other mothers throughout times and cultures. Knott describes this process: 'The telling of anecdotes, it is seeming to me, is a peculiarly powerful means of moving between history with a capital $\mathrm{H}$ $\ldots$ and the mundane stuff of living with an infant'. ${ }^{31}$ As a reviewer of Knott's book aptly describes:

The fragmentary nature of these anecdotes becomes an essential element of the book's fabric; Knott wants in part to capture the distracted, interrupted nature of new motherhood and often describes going about her research while trying to get her son to sleep or feed. ${ }^{32}$

In Baraitser's 2008 book, Maternal Encounters: The Ethics of Interruption, her view of the maternal state of mind is congruent with that of Knott's 'distracted, interrupted nature of new motherhood'. ${ }^{33}$ Baraitser seeks to present a major new theory of maternal subjectivity as well as discussing current understandings of contemporary motherhood in Western society. Baraitser's approach explores philosophies of feminist ethics, psychoanalysis and social theory. Like Knott, Baraitser cuts between her own anecdotes and theoretical concepts, reflecting the distracted, 'interrupted' characteristics of the maternal subjectivity described. Baraitser's 'ethics of interruption' goes beyond views of mothering as an interruption to an otherwise straight-forward inner life, but rather to articulate 'the potential within maternity for new experiences, sensations, moods, sensibilities, intensities, kinetics ... new coagulations of embodied and relational modes..$^{34}$

I argue that if matrescence is characterised by the messy, chaotic, interrupted and hard to define, as Knott and Baraitser describe, then the aesthetic techniques used to capture it would need to allow for the expression of these elements. I suggest that theories on immersion, affect and relation can lead us into a deeper understanding of the maternal experience by enabling affective encounters. In the following section, I give a brief overview of these concepts, which I suggest can shed light on the way the theme of motherhood could be explored in museum settings.

31 Knott, Mother, 5.

32 Stephanie Merritt, 'Mother: An Unconventional History - Review', Guardian, 10 March 2019, www.theguardian.com/books/2019/mar/10/mother-an-unconventional-history-childless-voicessarah-knott-lorna-gibb-review.

33 Ibid.

34 Baraitser, Maternal Encounters, 3. 


\section{Immersion, Affect and Relation}

Since Michel Foucault's 1969 The Archaeology of Knowledge, Foucault's theories of knowledge epistemes, power structures and regulatory spaces have been widely influential in scholarly work that highlights the power of the archivist to wield control over knowledge and the ordering of information. ${ }^{35}$ Museum scholars have written on the power that museums hold as history tellers. As museum scholars Fiona Cameron and Helena Robinson argue in their discussion of the documentation (or cataloguing) practices of museums, 'the act of description is not neutral'. ${ }^{36}$ They suggest that 'documentation is more than a repository of unadulterated "facts", rather, it constitutes an ideologically and culturally drenched form of text in its own right'. ${ }^{37}$ Characteristics such as date, medium and artist, while seemingly neutral, are not necessarily so. Museum scholar Laurajane Smith has written extensively about the power that museums wield as meaning-makers. In a critique of what Smith has termed 'authorised heritage discourse', Smith argues that heritage discourse works to reinforce national identity and mythology. In this model, the museum visitor plays a passive role and is not active in their relationship with museum content.

The theory of the 'relational museum', on the other hand, offers a new museology that emphasises museum's relationship with community. James Clifford's 1997 article 'Museums as Contact Zones' and Tony Bennett's 1998 Culture: A Reformer's Science point out that curators need to consider museums' roles as not just representers of communities but also as producers of knowledge and as institutions with various agendas. ${ }^{38}$ In the new museology, a curator is not a neutral preserver of history but is responsible for translating community histories for museum audiences. The relational museum is a suggested model in which the visitor is participatory in meaning making rather than being in a passive position as listener to an authorised heritage voice.

35 Michel Foucault, The Archaeology of Knowledge (London: Tavistock, 1972).

36 Fiona Cameron and Sarah Kenderdine, Theorizing Digital Cultural Heritage: A Critical Discourse (Cambridge: MIT Press, 2007), 240, doi.org/10.7146/mediekultur.v27i50.5244.

37 Ibid.

38 James Clifford, 'Museums as Contact Zones', in Routes, Travels and Translations in the Late 20th Century (New York: Harvard University Press, 1997); Tony Bennett, Culture: A Reformer's Science (California: Sage, 1998); For more information see Jones, 'Documenting Artefacts and Archives in the Relational Museum'. 
I suggest that digital tools could activate the relational museum model because they provide unique affordances to help us interact with heritage in an active way. VR in particular could hold the potential for museums to engage their visitors in a relational way. The relationship created between museum content and the visitor through VR could encourage multiple and fluid interpretations of museum collection material, beyond the information conveyed in the static museum object label, allowing the visitor to become an active participant in meaning-making. The concept of 'relation' is helpful in conceptualising the ways that a VR archive can benefit curatorial practice. Museum theorist Viv Golding suggests that the concept of relation offers much to feminist museum practice because it 'challenges essentialism - notions of purity, fixity and authority that echo in the traditional museum's masculine framing of knowledge in glass showcases. ${ }^{39}$ Relation requires being open to multiple meanings and interpretations of collection objects. Golding suggests this might mean curators reach out to artists or the general public to engage with collections in a way that allows them to contribute to the meanings of the object rather than this meaning being fixed. As Golding describes it, the imaginative realm of relation denotes a 'third space' of 'unsettledness, unhomeliness, rupture, as well as a new basis for cultural production'. ${ }^{40}$ As museum theorist Melissa Rachleff points out, museums are having to consider including visitor participation as part of their programs in order to stay relevant. The Rosenbach Museum and Library, for instance, was able to survive by opening its interpretative enterprise to artists in residence. The artists were encouraged to provide creative interpretations of the collection. Rachleff describes this: 'In effect this museum collection is being perpetually rediscovered, radically transformed and created anew by exposing itself to risks. ${ }^{31} \mathrm{VR}$ challenges the very idea of an 'authorised heritage discourse' by highlighting the process of interpretation. Australian curator and museum scholar Andrea Witcomb describes the multimedia exhibition in the context of the museum: 'This is a revolution which has revealed the process of making meaning in exhibitions, a process which previously was made to appear neutral through a focus on the conventional world of objects. ${ }^{32}$

39 Viv Golding, 'Museums, Poetics and Affect', Feminist Review, 104, no. 1 (2013): 80-99, doi. org/10.1057/fr.2013.2.

40 Ibid.

41 Cited in Elini Myrivili, 'Performativity, Interactivity, Virtuality and the Museum', Museology E-journal, 4 (2007).

42 Ibid., 35. 
The immersive and experiential potential of the virtual exhibit means that the knowledge transmitted to the visitor is embodied. Embodied learning is a way that the visitor can be engaged in a participatory relationship with the museum content. Digital humanities researcher and curator Sarah Kenderdine, who has authored a vast body of work concerned with digital museology, suggests that digital technologies have the capacity to produce an embodied experience of museum content and proposes the notion of 'embodied museography' as a way of thinking about these developments and immersive approaches. ${ }^{43} \mathrm{VR}$, which attains its power by captivating the viewer's attention to induce a sense of immersion and presence, can be a unique and ideal tool for exploration of subjectivity, as it places the viewer in someone else's lived reality. VR's power as a tool for embodiment and empathy has been addressed in scholarly research, but its capacity to reinvent the archive has not yet been investigated.

Thinking about the way 'affect' works in museums is also helpful for this discussion. More recently, 'an affective turn' in museum practice has focused on understanding better how museums make us feel. ${ }^{44}$ For example, a 2015 special issue of the Journal of Curatorial Studies focused on the role of affect in exhibition design. ${ }^{45} \mathrm{I}$ draw on discourse analysis academic Margaret Wetherell's definition of affect as 'embodied meaningmaking' as a definition that is useful in the context of the museum and the way content is exhibited to create affective encounters for the visitor. ${ }^{46}$

Witcomb and co-author Australian curator Kate Gregory have written extensively on affect in the museum, and suggest that affect can help achieve 'embodied learning' for the museum visitor. Witcomb and Gregory argue that exhibits hold the capacity to 'produce a different kind of knowledgeone that embodies in a very material way, shared experiences, empathy, and memory'. ${ }^{47}$ The observations made by Witcomb and Gregory reflect the ways digital technology could engage visitors as active participants in the heritage experience, in a relational museum model. It could be argued that the only real way to understand matrescence is to immerse

43 See Cameron and Kenderdine, Theorizing Digital; Sarah Kenderdine, 'Embodied Museography', About the Culture Academy Singapore, 23 (2012): 27.

44 Jenny Kidd, “Immersive" Heritage Encounters', The Museum Review, 3, no. 1 (2018): n.p.

45 Jennifer Fisher and Helena Reckitt, 'Introduction: Museums and Affect', Journal of Curatorial Studies, 4, no: 3 (2015): 361-2, doi.org/10.1386/jcs.4.3.361_2.

46 Margaret Wetherell, Affect and Emotion: A New Social Science Understanding (London: Sage, 2012), 4 .

47 Kate Gregory and Andrea Witcomb, 'Beyond Nostalgia: The Role of Affect in Generating Historical Understanding at Heritage Sites', Museum Revolutions: How Museums Change and are Changed (2007): 47. 
ourselves in a mother's experience. While cinema offers us a glimpse of the maternal, VR could take this immersion a step further, engaging us with the inner world of mothers and experiences of mothering.

In exploring the term 'immersive', I have drawn on museum theorist Jenny Kidd's analysis of the recent 'immersive turn' within museum contexts, in which Kidd suggests that immersive heritage practice has a number of key defining characteristics: 'it is story-led, audience and participation centred, multimodal, multisensory and attuned to its environment'. ${ }^{48}$ My analysis recalls the definition of immersion theatre theorist Nandita Dinesh who defines immersive as encounters that are 'multisensorial' and that privilege a 'participatory aesthetic'. ${ }^{49}$

While the terms 'immersive' and 'virtual' are trending in heritage publicity for MV programs, VR has only recently become a part of MV's content and so has not been fully explored in this heritage setting. ${ }^{50}$ In a broader sense, scholarly work on the use of VR in heritage settings is scarce. I begin my exploration in VR with a brief outline of its technology.

VR cinema is filmed on a static camera that can record in 360-degrees. This allows the viewer unlimited perspectives. The viewer wears a headset to watch the VR experience and is able to rotate and look at the complete 360-degrees, including along the vertical axis. VR has gained a reputation as an 'empathy machine', a phrase attributed to Chris Milk, founder of media company Within, known for the 2015 VR film Clouds Over Sidra (a collaboration with the United Nations and Samsung that takes users on a tour through Jordan's Za'atari camp for Syrian refugees). ${ }^{51}$ David Darg, cofounder of interactive-media agency Ryot, describes VR as 'the ultimate fundraising tool' because it can 'can create empathy like never before'. ${ }^{52}$

\section{Kidd, 'Immersive'.}

49 Cited in ibid.

50 For example, the MV website includes a 'Virtual Museum' online. Referring to MV's dinosaur display, the website's promotion states: 'Use this website to explore facts about the 17 skeletons of prehistoric animals on display in the exhibition.' The permanent exhibition at the Melbourne Museum is described as immersive: 'Touchable objects, immersive experiences and multimedia exhibits allow students to explore how these prehistoric animals moved, ate and survived in their changing environments.' This website is designed to be used as a teaching resource before and after a school excursions to the exhibition. In this instance, 'virtual' is used to refer to an online presence of aspects of the exhibition including text (written information about the dinosaurs) and images. For more information see 'Dinosaur Walk', Museums Victoria, museumsvictoria.com.au/melbournemuseum/resources/dinosaur-walk/.

51 Clouds Over Sidra, directed by Gabo Arora and Barry Pousman, 2015; Shamus Smith, Tim Marsh, David Duke, Peter Wright (1998) and Marie-Laure Ryan (2001) discuss VR's power as a tool for embodiment and empathy, cited in Elvia Wilk, 'Trauma machine: rewiring empathy with virtual reality', Western, 9 July 2018, popula.com/2018/07/09/virtual-reality-empathy-trauma/.2018.

52 Ibid. 
Several VR films demonstrate VR cinema's capacity to explore subjectivity, memory and trauma in the context of heritage; for example, Parragirls Past, Present unlocks memories of institutional 'care' drawing from oral histories of previous residents. ${ }^{53}$ Created by women who once lived at the institution Parramatta Girls Home, it is a deeply moving immersive VR film, which contains a 3D re-imagining of the institution site based on former residents' memories of the home. In this VR film, we see buildings of the institution, which have been drawn from former resident's memories, as we hear their recollections told in voice-over. This brings us in an intimate engagement with the memories of the residents. Chileanborn Australian VR artist Oscar Raby's VR work also offers an embodied experience of the intense trauma of war in an interactive virtual reality documentary Assent, which uses dream logic and video game aesthetics to depict the aftershocks of war. ${ }^{54}$ South Korean VR filmmaker Sojung Bahng's 2017 Floating Walk: Gangnam Kangaroo also brings the viewer into empathic engagement through Bahng's poetic voice-over narration and a 360-degree landscape that stiches together locales in South Korea (the filmmaker's home) and Australia (where the filmmaker currently lives) to recreate the inner-world of an international resident living and working in Australia, reconciling ancestral history and cultural identity. ${ }^{55}$ In this film we are able to experience the strange feeling of existing in two locales at once, coming into an empathic engagement with the unsettled emotions of immigration. As these examples illustrate, VR offers unique tools for empathic engagement, a feeling of presence, of having 'been there' at the site of the event or memory. It is these attributes that make it a technology worthy of contemplation in the cultural heritage field.

VR also offers a relational museum model with its capacity to present the visitor with an interactive archive. Through various software, from the more accessible and easy to use 'Wonda VR', to the more complex and multi-layered 'Unity', various levels of interaction between the viewer wearing the headset and the museum objects being displayed on the screen become possible. For instance, the viewer is able to navigate a menu of objects and by using the controls on the headset and can manually select which object they would like to learn about. Through gaze control, the

53 Parragirls Past, Present, writer/narrator Bonney Djuric, directed by The Parragirls Project, www.pffp memory.org.au.

54 Assent, directed by Oscar Raby, oscarraby.net/assent/.

55 Floating Walk, Gangnam Kangaroo, directed by Sojung Bahng, sojungb.com/floating-walkgangnam-kangaroo/. 
viewer only needs to merely look at an object on the screen to find out more about it or to even activate a new development in the narrative. In this way, 'relation' can be achieved in an active relationship between participant and museum content. Objects then become filled with meaning personal to the viewer, as they are able to come into an intimate engagement with them. In my VR experiment with everyday objects of mothering, VR has enabled me to imbue objects with affect.

In my 'mother archive' I have explored various ways to illuminate experiences of motherhood, and have investigated how VR experiences might enact embodied museography in museum practice.

\section{The Mother Archive-Practice}

As part of the process of creating the 'mother archive', I draw on the affective potential of sound by audio-recording everyday experiences with my daughter. My project experiments with teaming voice and material culture to create a relationship between material objects and digital sounds. In my attempt to articulate my own feelings about mothering, I have found, as Sarah Knott discovered in her research for book Mother: An Unconventional History, it is the banal sights and sounds that best demonstrate the realities of my experiences. ${ }^{56}$ I suggest then that the representation of the maternal in museum programs should involve an immersion in the daily realities of mothering and that a mother archive would need to contain collection objects pertaining to everyday realities.

\section{'Glow-face': Affect and Everyday Objects}

In my experiments with creating a digital archive of motherhood, I have reflected on the objects of matrescence that hold the most potence for me. One of these is our night-light.

It is this everyday object that I find captivating as it holds within it the emotions I felt in early parenting. A hallmark of early parenting for me was night-time. In many ways, it felt like this was when the work began. My daughter slept in the day but at night she woke, endlessly it seemed, for milk. It was in the half dark that we got to know each other;

56 Knott, Mother, 5. 
when she gave me her first smile, when she saw me. We called it 'glowface' because we didn't know what is was. Two-parts: unicorn and dog, it glowed, guiding us from room to room, from couch to breast to bed and back to couch again. In my VR work, I have brought glow-face to life. It moves and rotates around the dark 360-degree space that surrounds us so that we are able to feel it animated. Emanating a dull ever-switching colour, 'glow-face' - a name reflective of our inability to articulate in the trenches of sleep-wake caring - has its own personality, its own aura. We hear the rituals of night-time parenting on the soundtrack: a lullaby is half-sung, a baby monitor gurgles, the sound of breath pulses in the dark.

As Knott reminds us, night-time mothering is one of the key aspects of mothering that has been neglected in history:

In bed so many hours of each twenty-four, and wake for so many of those hours, I suspect that the middle of the night is maternity's most concealed past. Hard to fathom, yet perhaps most important to a person mothering. ${ }^{57}$

To display a simple night-light without personal context would not activate affect in a museum setting. In order to convey the object's personal significance and the object's affect, the curator would need to somehow bring the object to life-to animate it and to enable the visitor to feel connected to it, if not through physical touch, then through a sense of intimacy with the object. In my VR experiment, VR allows me to create this sense of intimacy. Hearing sounds associated with nighttime rituals also enables affective encounters with this everyday object and the lost history of night-time mothering. The intimate encounters with everyday objects afforded by VR technology resist grand narratives described by Laurajane Smith as hallmarks of authorised heritage discourse and instead work in a relational museum model and enables affective encounters. 


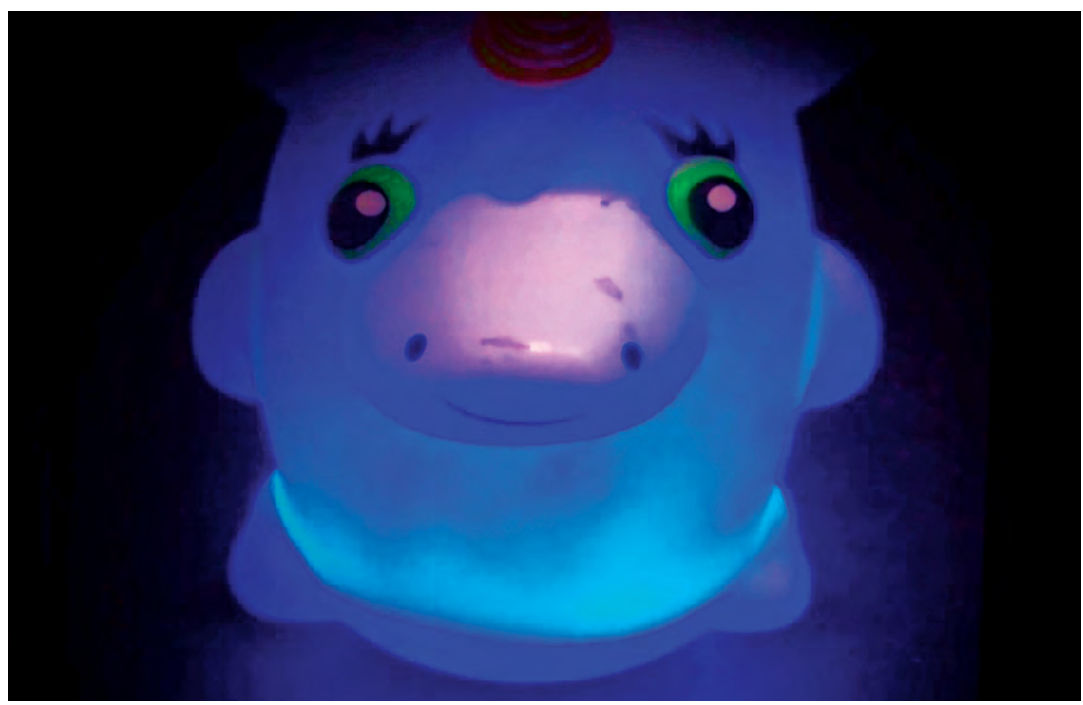

Figure 1: Glow Face.

Source: Rebecca Louise Clarke.

\section{Timelessness and Immersion}

When I audio-recorded my daughter over the course of a day it was in an attempt to see if I could capture a day in the life of my mothering. What resulted was an eerie sense of time becoming a loop, each activity and its sound repeated to the point that every day, every hour becomes indistinguishable from the next. Knott describes timelessness as being an important component of maternal subjectivity: 'There's just one long, blurry present, counted out in the days of the baby's age. Or maybe my days since the birth', writes Knott, of her own mothering. ${ }^{58}$ In a bright 360-degree daylight scene of a backyard, we see my daughter running. We hear the sounds over the course of a typical day of parenting, each sound growing more warped and repetitive. My toddler runs in circles around us. Her Dad is chasing her in a game she calls 'tiger'. The game is happening now, in the past, in the future, as they run around the circular landscape over and over. It could be one game or several, over the course of a day, or a week. Dad growls (he is tiger) and she screams, laughs, screams, laughs. When I watch this scene, I feel a sense of anxiety which I did not create intentionally but which has emerged regardless, an everpresent threat of things going sour, the feeling of 'it'll end in tears' as my 
mother used to say. It doesn't 'end in tears' but instead cycles, in a loop, through tears, laughter, screams, tired cranky pleas, and returns again to a game of 'one more' tiger.

While the voice is an area of museum studies not fully explored, in the context of radio, it has been given more attention. In a discussion of oral history narratives in radio programs, journalist Siobhan A McHugh offers insights into the relationship between orality, aurality, and affect:

An affecting testimony will ... arouse strong feelings in the listener, which will, in turn, influence how the listener processes the story and evaluates its meaning (cognition). Put simply, the affective power of sound and voice, combined with the intimacy of the listening process, means we can be moved by listening to oral history; this, in turn, affects how we absorb and retain its content, as well as how we judge that content. ${ }^{59}$

My VR scene brings the viewer into an everyday scene of motherhood. It does this not through a linear narrative or through narratives of nationhood or monumental moments in history. Rather, these scenes linger in moments of timelessness and chaos, resisting finality. In this way, my experiments with the technology work in the poetics of relation, and enable affective encounters through VR immersion. Through the presence that VR offers, the distance between subject (viewer) and object (what we see on screen) is brought into intimacy. Instead of the viewer merely observing the scene, the viewer in the 360-degree sphere is able to look around the backyard and feel that they are in the scene.

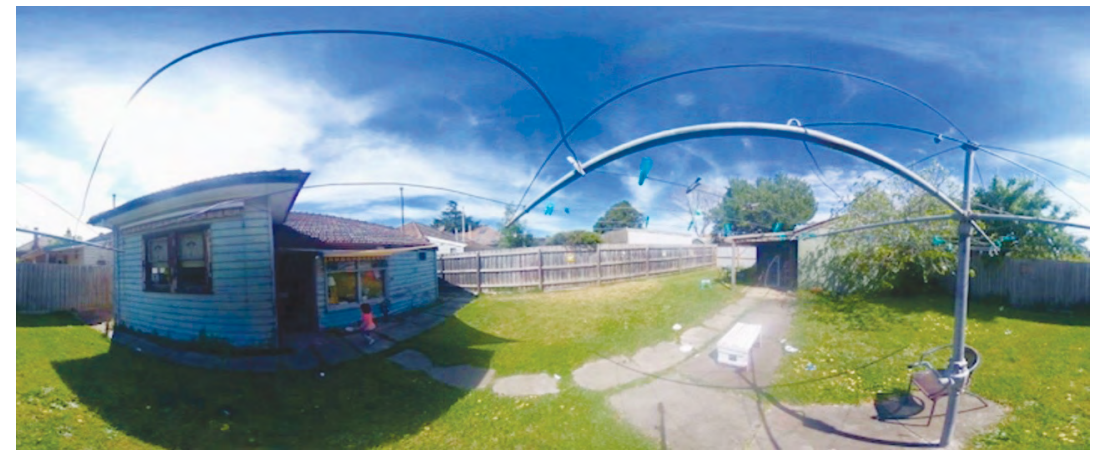

Figure 2: My daughter playing 'tiger'.

Source: Rebecca Louise Clarke.

59 Mia Lindgren and Siobhan A McHugh, 'Not dead yet: Emerging Trends in Radio Documentary Forms in Australia and the US', Australian Journalism Review, 35, no. 2 (2013): 101. 
In these instances, VR has enabled me to create representation of an 'interrupted', chaotic and repetitive state of mind typical of my day-today life as a mother, of what it is like to live a moment in my life as a Mum. Witcomb argues that exhibits hold the capacity to 'produce a different kind of knowledge-one that embodies in a very material way, shared experiences, empathy, and memory ${ }^{60} \mathrm{VR}$, with its potential to create immersion, can offer the 'physical expressions and material effects' that Witcomb describes of immersive exhibits. ${ }^{61}$ It also offers us intimate encounters with collection objects and the potential to become a part of the archive, to interact with it and to navigate it ourselves, activating affect and the poetics of relation. This approach to museum practice works to resist the grand narratives described by Smith as being hallmarks of authorised heritage discourse, and instead seeks to find those spots in maternal histories reminiscent of those found by Knott in her discovery of histories of mothering, those that linger 'between history with a capital $\mathrm{H}$ $\ldots$ and the mundane stuff of living with an infant'. ${ }^{62}$

\section{Conclusion}

In this article I have asked: how can we represent the inner-world of mothers and 'maternal subjectivity' in museums? Providing an analysis of MV's mother-related material culture, I observe an absence of motherhood as a thematic focus in museums. I then go on to explore how museums might best represent complex features of maternal experiences. I have suggested that the model of the relational museum, affect and techniques of immersion, in particular VR, offer valuable tools for museums to engage with the subject of mothering in innovative ways, which can work outside stereotypical narratives about motherhood.

VR's power to achieve embodiment and empathy has been addressed in scholarly research, but its capacity to reinvent the archive has not yet been investigated. My immersive archive aims to achieve a more expansive representation of maternal subjectivity by exploring what becomes possible when we approach the archive in new and exciting ways. I explore the potentiality of affect and empathy in museum practice, arguing that

60 Andrea Witcomb, The Materiality of Virtual Technologies: A New Approach to Thinking About the Impact of Multimedia in Museums (MIT Press, 2007), 47.

61 Ibid.

62 Knott, Mother. 
exhibitions that re-imagine and reframe collections have the unique capacity to create embodied and empathic responses. This engagement with the empathic and affect has pedagogic potential to enable younger generations to engage with histories of the past. Empathic response can be achieved by engaging with collection material in an embodied way.

Beyond the scope of this article, but in need of further analysis is the role of language and description in the archiving process, and how these would need to be re-considered in an imagining of an archive about motherhood. In the conception of the creative archive, new innovative ways to search for material can co-exist with more conventional forms of searching. The ontology that underpins the values of MV would need to be explored. Innovative approaches to archival language could make room for a collection that addresses individual experiences of mothering. Inspired by personal stories of participants responding to the subject of motherhood and my own personal experiences as a mother, my immersive archive explores the potential of affect in its representation of artefacts. I suggest that immersive exhibitions challenge the very idea of an 'authorised heritage discourse' by highlighting the process of interpretation. At the heart of my imagined collection, articulated in sound and image, is my exploration of affect, immersion and the messy, hard to define and neglected field of maternal experience. 
This text is taken from Lilith: A Feminist History Journal: Number 26, published 2020 by ANU Press, The Australian National University,

Canberra, Australia.

doi.org/10.22459/LFHJ.26.03 